\title{
Entre normativas y disidencias. Políticas sexuales en Argentina y Chile durante el siglo XX
}

\section{Between Regulations and Dissents. Sexual Politics in Argentina and Chile during the $20^{\text {th }}$ Century}

\section{Juan Carlos Garrido Gamboa* y Patricio Simonetto**}

RESUMEN: En este artículo se propone un estudio comparativo de las políiticas sexuales en Chile y Argentina en dos aspectos: primero, las leyes de restricción urbana hacia las prácticas sexuales disidentes y, segundo, las resistencias desde organizaciones políitcas a partir de la década de 1930. La legislación violenta contra las disidencias sexuales y la transición a la democracia de ambos países abrió el debate en torno a las disputas sobre el carácter sexuado de la ciudadanía y los cuestionamientos en torno a las leyes imperantes. Con base en este enfoque de historia comparada y en la revisión de fuentes documentales y bibliográficas, se comprueba la complejidad en la aplicación y aceptación de políiticas sexuales.

PalabRAS ClavE: LGTB; Políiticas Sexuales; Argentina; Chile; Historia Comparada.

ABSTRACT: This work proposes a comparative study of sexual policies in Chile and Argentina, in two aspects: first, the laws of urban restriction towards dissident sexual practices and, second, the resistance from political organizations since the 1930 s. Violent legislation against sexual dissent and the transition to democracy in both countries opened the debate about disputes over the sexed nature of citizenship and questions about the prevailing laws. Based on this approach of comparative history and the review of documentary and bibliographic sources, the complexity in the application and acceptance of sexual policies is checked.

KEY WORDS: LGTB; Sexual Politics; Argentina; Chile; Comparative History.

Recibido: 20 de octubre de 2018

Aceptado: 18 de febrero de 2019

Universidad de Chile (carlosgarridogamboa@gmail.com).

"* Universidad Nacional de Quilmes-Conicet (patriciosimonetto@gmail.com). 
L a sexualidad, los sentidos y prácticas circunscritos por la modernidad en este campo, fueron objeto de intervención de diversos actores durante el siglo XIX y XX en occidente. Aunque toda política tiene un carácter sexuado, los Estados modernos y actores que colonizaron sus instituciones como médicos, juristas e intelectuales, intentaron modularla mediante programas de educación, campañas profilácticas, censura de publicaciones "obscenas", la regulación de la prostitución, entre otras. Acciones sobre un territorio que percibían que cambiaba con las nuevas posibilidades que ofrecía el anonimato de las metrópolis en crecimiento, la creciente expansión de tecnologías que distanciaron la reproducción del placer y la visibilidad creciente de prácticas e identidades sexuales disidentes. Nos referimos a la disidencia sexual como las prácticas, deseos y sentidos, no siempre codificados como una identidad, que difieren de la heterosexualidad como un valor cultural dominante. En este contexto, la(s) sexualidad(es) fue(ron) presentada(s) como un prisma de la nación, de su construcción y su orden, en el que se canalizaron las preocupaciones modernas por la reproducción cualitativa y cuantitativa de la población (Stearns 2017). Mediados por discursos de circulación global y sus traducciones locales, que ampararon cercenamientos de libertades, pero también ampliaciones de políticas sociales, diversos agentes se preocuparon por reinventar sus naciones entrometidos en las alcobas de sus patrias (Corrales y Pecheny 2010: 3).

El presente artículo propone un estudio comparativo de las políticas sexuales en Chile y Argentina durante el siglo xx, focalizándose en las sexualidades disidentes y los movimientos de diversidad sexual. Para esto, abordaremos dos áreas de estas políticas: Primero, las normativas y prácticas con las que las agencias del Estado definieron los límites sexuados de sus ciudadanías y construyeron una frontera binaria entre lo heterosexual y sus disidencias, en particular, las políticas de control urbano en Argentina y Chile durante el siglo Xx. Segundo, nos proponemos restituir las formas de organización políticas con las que cuestionaron el accionar estatal, partiendo de nuestras investigaciones sobre los casos nacionales (Simonetto 2016; 2017a; 2017b; 2018; Garrido 2017; Garrido y Barrientos 2018), para analizar diversos puntos de divergencias y convergencias entre ambos países. 
El texto abordará dos argumentos. Primero, aunque en Chile las leyes de penalización de la sodomía fueron incluidas en el código penal en el siglo XIX mientras que en Argentina el delito se derogó en 1886, ambos países coinciden en una ampliación de prácticas restrictivas a partir de la década de 1930. Esto se debió a la redefinición de las políticas sexuales encarnadas en agencias estatales como producto de cuatro procesos simultáneos: las crisis de los proyectos políticos, culturales, económicos y sociales de los liberalismos argentinos y chilenos generada por la crisis de 1929; el crecimiento exponencial de las ciudades como producto de la migración interna o externa y el debilitamiento de las formas de control comunal; la creciente consolidación de la homosexualidad como una identidad sexual moderna y visible; y la circulación de narrativas globales sobre los peligros de una sexualidad descontrolada. De esta forma, la idea de "moral pública" se condensó en distintas normativas que fueron variando, como por ejemplo la Ley de Estados Antisociales en Chile (1950) o los códigos de falta provinciales en Argentina, que buscaron definir el carácter de género, clase, edad y etnia del espacio público. La moral y las formas de violencia derivadas conectaron a la sexualidad y la política como metáforas del orden. Dichas políticas provocaron formas heterogéneas de resistencia durante la segunda mitad del siglo Xx. En los casos de Chile y Argentina, las salidas democráticas a los regímenes dictatoriales generaron una serie de disputas en las que se redefinió el carácter sexuado de la ciudadanía y, a su vez, colaboraron con un proceso de progresiva integración de los movimientos de diversidad sexual a los regímenes democráticos-liberales. Por nuestras trayectorias de investigación nos centraremos en organizaciones lideradas centralmente por homosexuales varones. ${ }^{1}$

Estudios recientes cuestionaron la búsqueda de generalizaciones comparativas ajustadas a los Estado-nación modernos como una impronta europeizante y se invitó a reflexionar posibles estrategias de integración re-

1 Reconocemos la existencia de diversos activismos, identidades y prácticas lésbicas, travestis y transexuales, entre otras, sin embargo y para efectos de este artículo, nos concentramos en la homosexualidad masculina centrados en nuestras trayectorias de investigación. 
flexiva regional (Prado 2013). El problema reside en cómo establecer una escala común, es decir, cómo elegir una problemática semejante entre actores mediados por experiencias históricas disonantes (Boholavsky 2015); en este caso, la necesidad de buscar aristas de análisis en las políticas civiles o estatales. En esta dirección, nos inscribimos en una perspectiva que, anclada en la comparación y las conexiones, forma parte de una apuesta por entrever procesos que trascienden las fronteras políticas (Drayton y Motadel 2018), como también forma parte de los esfuerzos globales para historiar la(s) sexualidad(es) como un elemento constitutivo de los procesos sociales y culturales (Balderston y Guy 1997; Stearns 2017; Herzog 2011; Touler y Fisher; 2013). En Argentina y Chile el estudio de las sexualidades disidentes fue abordado desde distintas perspectivas. Se detalló la construcción discursiva y medicalizada de los comportamientos sexuales considerados patológicos (Bao 1993; Ramacciotti y Valobra 2008; Salessi 1995; Cornejo 2011; Contardo 2011; Vëto 2018); se abordó a los movimientos homosexuales radicales (Barrancos 2014; Simonetto 2017; Robles 2008; Sutherland 2009; Garrido 2017; Garrido y Barrientos 2018); se estudiaron mecanismos de represión y restricción legal (Sabsay 2011; Simonetto 2016; Garrido 2016) y se bosquejaron figuraciones socioafectivas entre personas del mismo sexo (Acha y Ben 2004; Figari 2009; Simonetto 2017b y 2018; ). Considerando los estudios existentes, nuestra propuesta se organiza en dos apartados. El primero describe el contexto y las políticas de restricción a las sexualidades disidentes en Argentina y Chile, y el segundo estudia las formas de resistencia organizadas o no durante la segunda mitad del siglo XX en centros urbanos.

REORDENAR EL TERRITORIO:

POLIITICAS DE RESTRICCIÓN A LAS SEXUALIDADES DISIDENTES

El crecimiento exponencial de las ciudades latinoamericanas desde mediados del siglo XIX y XX se caracterizó por su inserción en el mercado global como exportadores de materias primas, la pronta modernización 
arquitectónica de los centros urbanos, la afluencia de inmigrantes externos e internos y la importación de bienes y servicios como el transporte. Dichas características redefinieron las condiciones materiales para el erotismo y el afecto, lo que potenció la emergencia y consolidación de las identidades sexuales modernas (Hubbard 2013). La extensión de espacios de sociabilidad interclasista se produjo en paralelo con el debilitamiento de los lazos de control familiar, condiciones para la codificación de prácticas homoeróticas en múltiples identidades sexuales que definieron las fronteras entre heterosexualidad/otros (Chauncey 2008).

En América Latina, las relativas escasas ofertas en el mundo agrario desplazaron a importantes franjas de pobladores a las ciudades en búsqueda de oportunidades a finales del siglo XIX y principios del XX (Gilbert 1997). Entre 1880 y 1930, Buenos Aires consolidó su centro urbano al ubicar como principal puerto del país: se modernizó rápidamente con la importación de bienes manufacturados y tecnológicos, como el desarrollo del subterráneo y el sistema sanitario. Su construcción como ciudad nodo la transformó en un foco receptor de migrantes ultramarinos cuyo punto cumbre llegaría en 1947 para ser reemplazado progresivamente por migraciones internas, situación que colaboró con la concentración de mano de obra masculina joven en la ciudad, lo que trastocó las configuraciones de género (Barrancos 2006, Gayol, 2000). La crisis rural de 1929 ensanchó la ciudad por que potenció la llegada masiva a los cordones conurbanos de las zonas rurales (Gorelick 2004). Así, entre 1947 y 1980, la provincia de Buenos Aires creció proporcionalmente casi al doble, de 15893827 habitantes pasó a 27949 480, la mayoría en las zonas metropolitanas (Gobierno de Buenos Aires 2014). En Chile, el proceso de industrialización desde principios del siglo xx y el incremento del tamaño del Estado en Santiago ofreció una diversidad de actividades laborales como la construcción de obras públicas, el servicio doméstico y el servicio militar, que atrajo a miles de migrantes (Romero 1997).

La vorágine de transformaciones materiales y el crecimiento populoso acrecentado tras la migración por la crisis de 1930 fueron componentes decisivos en la solidificación de las prácticas sexuales homoeróticas y en 
la percepción de las elites locales de la disolución de las condiciones materiales de la identidad nacional. La crisis de la ciudadanía liberal pensada para varones blancos, heterosexuales y propietarios demandó la formulación de nuevas políticas de control sobre el espacio urbano como un intento desesperado de restablecer fronteras percibidas como flexibles (Simonetto 2016), amparados en discursos moralizantes médicos, religiosos y/o reformistas. Durante el siglo xx las normas se actualizaron y refinaron en vistas de definir los parámetros de regulación social, sexual, política y clasista del espacio. La penalización de figuraciones sociales disidentes se apoyaba en el temor por la desaparición de fronteras sustanciales de cierta subjetividad pública asentada en una ciudadanía imaginada (Sabsay, 2011). La moral institucionalizada en las normas resultó un registro donde agentes estatales se imaginaron a sí mismos como portadores de una cualidad que ya no estaba contenida en la población civil y que actualizaban en su práctica (Simonetto, 2016), gestándose una "autoridad moral" desde agentes policiacos contra expresiones sexuales disidentes.

$\mathrm{Al}$ calor de las recomendaciones internacionales canalizadas en torno a la prostitución y la pornografía por la Liga de Naciones (Herzog 2011), en Argentina la preocupación se condensó en los debates sobre la "moral pública". La misma refería a una noción de orden en la que sexualidad y política actuaron como metáforas complementarias y construyó el corazón de políticas restrictivas del uso del espacio que perduraron a la alternancia de gobiernos civiles y militares durante el siglo XX (Simonetto 2016), al igual que en otros países como Brasil (Cowan 2016), la dictadura de José Uriburu sancionó mediante el decreto 32265 en 1932 los edictos policiales que contenía el artículo $2 \mathrm{H}$ que castigó la presencia de homosexuales en el espacio público con menores de edad. La preocupación militar por el control social se explica por la mixtura de la cultura católica con la castrense, cuyo síntoma fue la confesión obligatoria en los cuarteles. Con este parangón ideológico los militares se definieron como un subgrupo independiente al interior de la nación, con autoridad moral y política para intervenir gobiernos democráticos y "reordenar" la patria (Soprano 2016). 
En Chile, inspirado en las normas del código español de 1822, el código penal de 1874 contuvo diversas consideraciones religioso-morales antes que un paradigma médico de la homosexualidad (Cornejo 2011). Este aspecto se reflejó en dos leyes que intentaron normar las prácticas sexuales y morales en el país: el artículo 365 que castigó la sodomía -es decir, el acto sexual entre dos hombres-, y el artículo 373 que decía "de cualquier modo ofendieren el pudor o las buenas costumbres con hechos de grave escándalo o trascendencia" y hacía referencia a las prácticas que atentaran contra las normas morales y sexuales de la época, lo que reforzaba la heteronormatividad en la sociedad chilena. Ambos casos, si bien no lo señalaron explícitamente, se caracterizaron por dos puntos: 1) criminalizar las prácticas y actos no heterosexuales, además de cualquier expresión de género que no correspondiera al sexo de la persona - principalmente si pensamos en el artículo 373-, lo cual afectaba a personas que no tenían prácticas o relaciones heterosexuales; 2) le concedían a la policía una "autoridad moral" que le permitía castigar, criminalizar y hostigar a estos actores, lo que implicaba altos niveles de violencia sin aparente control. Así, la noción de "moral pública" en Argentina y Chile reforzó los parámetros heterosexuales del modelo de "ciudadano" que sus Estados modernos pretendían construir.

Si durante el siglo xIx la "moral eclesiástica" fundamentó las leyes chilenas, desde la década de 1930, la penalización de la sodomía se basó no sólo en argumentos morales, sino también en discursos científicos (Cornejo 2011). Durante el gobierno de Carlos Ibáñez del Campo se fundó Carabineros, primera institución policiaca que, dentro de sus acciones, se encargó de cumplir las leyes contra la sodomía en las calles, bares, casas, entre otros lugares (Alegre 2017), de hecho, en 1954 se promulgó la Ley de Estados Antisociales cuyo objetivo fue categorizar a sujetos potencialmente "tóxicos" para la nación; dentro de algunas categorías se consideraba a vagos, ebrios y homosexuales (Contardo 2012). En este escenario, la violencia contra las sexualidades disidentes se legitimó tanto desde autoridades policiales como desde los mismos civiles, muchas veces siendo 
denominados como "colipatos", "travestis", "maracos" y "yeguas sueltas" (Acevedo y Elgueta 2009).

Durante los tiempos de la Unidad Popular, las leyes morales del Código Penal asumieron una nueva connotación: la supremacía masculina y el rechazo hacia la homosexualidad serían parte de la figura del "hombre nuevo" que representaba la izquierda chilena y latinoamericana. En este contexto, los "hombres antinaturales" serían aquellos que no representaran estos valores sobre masculinidad revolucionaria que defendían grupos como el MIR (Power, 1997; Mallon 2003; Acevedo y Elgueta 2012). La primera manifestación protagonizada por personas homosexuales y travestis en la Plaza de Armas en 1973 fue reprimida por autoridades policiales usando el artículo 373 del Código Penal. El intendente de Santiago, Julio Stuardo, señaló en un periódico que usaría la fuerza pública para impedir "cualquier ultraje a la moral y las buenas costumbres", nuevamente respaldaba las leyes existentes para criminalizar y castigar las prácticas disidentes (Robles 2008).

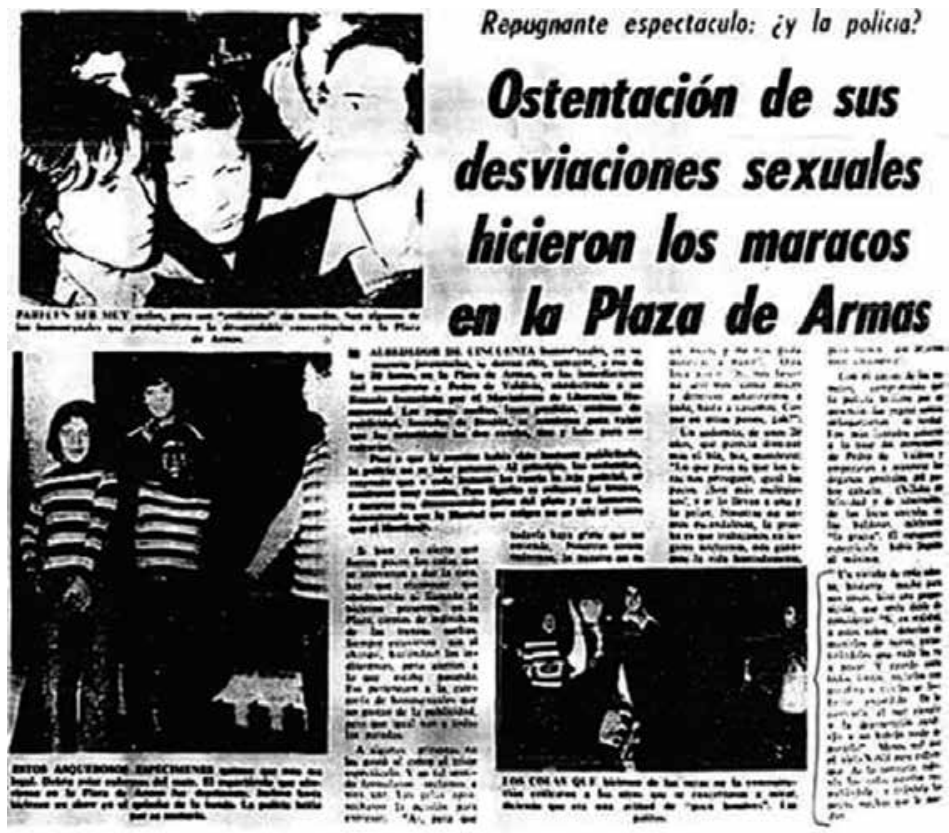

FuENTE: Diario Clarín, 24 de abril de 1973. 
En Argentina, en la primera parte del siglo xx hubo una mayor diversificación de normas penalizadoras contra los homosexuales. Desde 1933, en la ciudad de Buenos Aires se condenó a los varones que ostentasen intenciones sexuales en compañía de un menor, con lo que se sancionó el merodeo de homosexuales. En 1945 el peronismo creó una comisión para diseñar un código de faltas de la provincia de Buenos Aires. Las primeras normas condensaron, al igual que otras provincias, bajo la figura del escándalo el castigo, a quien ofreciera sexo en público, con lo que se castigó a prostitutas y a homosexuales (Decreto 378/45). Dicha ley tuvo semejanzas con el artículo 373 chileno sobre ofensas al pudor, moral y buenas costumbres, normativas que definieron a la moral pública al condenar prácticas "ofensivas" para la nación. En Argentina, desde 1950 se le brindó el estatuto de juez de falta al policía, lo que fortaleció la aplicación de estas normativas (Decreto 873/50).

En esta dirección, los regímenes castrenses promulgaron reformas ampliadas por gobiernos civiles. En 1956, el gobierno militar transformó los códigos en ley, estableciendo penas económicas que de no ser abonadas implicaban una corta detención en el calabozo (Ley Provincial 5571). Los códigos trataron de limitar las capacidades de acción y sociabilización de "izquierdistas", "amorales" (varones homosexuales), "prostitutas" y "desordenados" (pobres urbanos). El régimen de 1955 penó actividades contrarias a sus objetivos políticos: pintar paredes con frases disruptivas o repartir volantes. Se tipificó la "vagancia" al condenar a quienes mendigaran teniendo aptitudes físicas para trabajar, lo que al mismo tiempo penó a los varones de "malos hábitos" que estuviesen acompañados de un menor o se ofrecieran en público. La reforma impulsada en 1966 incrementó las facultades policiales, se equiparó a los homosexuales con las meretrices para limitar su sociabilidad sexual y afectiva en espacio públicos y privados apelando a la figura del escándalo, y se condenó como "explotación de credulidad pública" la actividad de aquel que "en la vida diaria se vista y se haga pasar como persona del sexo contrario" (Dec. Provincia N22, 1966). Entre 1973 y 1980 se ampliaron las multas y facultades de la policía sobre el territorio. También se permitió, mediante la Ley 803 , que los mayores de 16 años denunciasen infractores y el aviso a las familias en caso de detener un menor. 
Las dictaduras militares en el Cono Sur intensificaron la criminalización de la disidencia sexual. Dicha violencia se caracterizó por la imposición de tareas "femeninas" a homosexuales y trans, control policial en la vía pública y espacios privados y, en ciertas ocasiones, el asesinato emprendido por grupos policiales o civiles - como el Escuadrón Hortela en Brasil y el Comando Cóndor y Moralidad en Argentina— (Mott 1996; Figari 2009). En Argentina, las diversas dictaduras en el siglo XX usaron las restricciones policiales que trascendieron los cambios de gobierno como, por ejemplo, desde 1966 el régimen de Juan Onganía acentuó las razzias (redadas) como método de detección callejero. El periódico Clarín festejó que la "moral no pasa de moda" y apoyó que persiguiera a quienes "bajo el argumento de que los tiempos cambian han desnaturalizado la función reservada a los parques y plazas, con la que provocan a veces situaciones desagradables, aún para los mojigatos" (Clarín 1966). El diario Crónica presentó en la sección policial un informe diario de los allanamientos; una revisión del primer año del gobierno de Onganía (1966-1967) permitió contabilizar un total de 4 752 detenidos sobre una base más amplia de personas sometidas a cacheos, detenciones en la vía pública y revisión de antecedentes. Entre los mismos se presentó un mapa complejo que incluyó homosexuales, pobres urbanos, ebrios y jóvenes desarreglados (Simonetto 2016). Además, aquellos varones que buscaban sexo por las calles porteñas tuvieron que lidiar con el chantaje de oficiales que se hacían pasar por potenciales parejas para luego obtener una ganancia, o de varones de los sectores populares que, tras participar del acto sexual, los robaban (Simonetto 2018).

Ni la dictadura militar chilena y el Proceso de Reorganización Nacional en Argentina tuvieron una política focalizada en perseguir a homosexuales, travestis o lesbianas, sin embargo, las normativas existentes respaldaron violencias específicas contra esta población. En ambos casos, las décadas de 1970 y 1980 fueron un periodo de redadas policiales: en Chile, por ejemplo, se aplicó el artículo 373 de ofensas al pudor y buenas costumbres hacia mujeres trans o en discoteques gays nocturnas, como parte de la violencia generalizada ejercida en la época (Garrido 2016). La cualidad de dicha ley es que, al tener su origen en el siglo XIX, en el contex- 
to más contemporáneo tenía características poco claras al hacer referencia al "pudor, moral y buenas costumbres", por lo mismo, dio espacio para una libre interpretación de las autoridades policiales (Contardo 2011). Lo mismo ocurrió con la ley de penalización de la sodomía que castigaba las prácticas sexuales entre hombres, la cual fue usada por militares y carabineros para condenar a mujeres trans que sufrieron violencia, acoso sexual y humillaciones en las comisarías (Garrido 2016).

Las transiciones democráticas habilitaron un escenario paradójico en el que se abrió un escenario de disputas contra las normativas de control del territorio, pero a pesar de ello, como en el resto del siglo XX, las normativas de penalización a la disidencia sexual continuaron en las primeras generaciones de gobiernos posdictatoriales y, una vez disueltas, las prácticas policiales tendieron a seguir castigando a ciertos sectores, en particular, a las mujeres trans. En la década de 1990 en Chile, se siguen aplicando los artículos 365 y 373 por medio de redadas policiales, detenciones arbitrarias y violencia policial, en lugares frecuentados por homosexuales y personas trans. Algunos de estos operativos se siguieron realizando en discotecas o cines de público gay, realizando allanamientos y hostigamientos acompañados de insultos como "maricones" o "hediondos a mierda", atacando a homosexuales sin algún justificativo delictual, sino por estar "transgrediendo la moral y buenas costumbres", según lo estipulado en la ley (Barrientos y Garrido 2018). Desde la década de 1980 hacia adelante, otro elemento que legitimó este tipo de violencia fue la crisis del VIH-sida, infección que se vinculó directamente con la homosexualidad. Los diversos prejuicios asociados al VIH y la homosexualidad, así como la promiscuidad y degeneramiento sexual, modelaron una opinión pública que validó formas de violencia social particularmente contra hombres gay y personas trans (Guajardo 2018).

En síntesis, la comparación de las normativas y aplicación de punición a la disidencia sexual en Chile y Argentina permiten establecer algunos puntos de convergencia. Primero, que la solidificación de las directivas en torno a la moral pública y el progresivo poder otorgado a las agencias de aplicación (policías) estuvo asociada a una respuesta de las elites estatales frente a una presunta amenaza a las condiciones materiales de su 
identidad nacional. En este sentido, frente a las crisis del proyecto liberal en América Latina y la identificación de las perturbaciones de las formas modernas de vida urbana, intentaron establecer políticas de control que redefinieron las fronteras sexuales de la ciudadanía. En segundo lugar, a pesar de la alternancia entre gobiernos civiles y militares, la intensidad de aplicación varió en la medida en que lo moral funcionó como una metáfora en la que sexualidad y política convergieron para definir un sentido de orden, las normativas sancionadas constituyeron un hilo de continuidad que entraría en declive a finales del siglo XX.

RESISTENCIAS Y DESINTEGRACIÓN: MOVILIZACIÓN Y ACCIONES CONTRA LAS RESTRICCIONES SEXUALES ESTATALES

A partir de la década de 1960, la convergencia entre la consolidación de las identidades sexuales disidentes modernas, las nuevas expectativas generacionales despertadas con la emergencia de la juventud como un actor político de modernización social y cultural, las transformaciones en las culturas de las nuevas izquierdas y los feminismos, y el clima de radicalidad política, crearon las condiciones para la visibilización de los primeros movimientos homosexuales radicales. Las convulsiones políticas, culturales y sociales transformaron profundamente la política en los centros urbanos del occidente global (Scheuzger 2018), lo cual también se expresó en la crisis de la izquierda tradicional liderada por los partidos comunistas amparando la gestación de grupos con nuevos imaginarios de la revolución social. En los centros urbanos, las capas medias y los jóvenes politizados de las universidades fueron la base social de una nueva agenda en la que sexualidad y política tuvieron puntos de encuentro (Cosse 2017). La reinterpretación radical de la identidad homosexual funcionó como una apropiación positiva de la diferencia de un concepto acuñado en clave patológica por los discursos médicos hasta mediados del siglo XX (Figari 2010: 227).

En Argentina, la radicalidad política se extendió ligada a la proscripción del peronismo. La resistencia al régimen militar y la movilización activa de trabajadores y estudiantes que se expresó en el Cordobazo (1969) 
fueron un telón de fondo de la emergencia de una interpretación radical de la homosexualidad. En 1967, Héctor Anabitarte, un militante sindical del gremio del correo, fue sancionado, enviado al psiquiatra y finalmente expulsado del Partido Comunista por proponer un debate sobre la homosexualidad entre los jóvenes. Fundó el Grupo Nuestro Mundo junto con un militante del sindicato de empleados estatales, un vendedor de máquinas de escribir y un joven vendedor de seguros, entre otros. En 1970, en la Facultad de Filosofía y Letras de la Universidad de Buenos Aires se fundó el grupo Profesionales, impulsado por alumnos y profesores, entre los que se destacó el sociólogo y poeta Néstor Perlongher, quien se había alejado de un grupo trotskista. En 1971 ambos grupos confluyeron y conformaron el Frente de Liberación Homosexual (FLH), una organización multitendencia, que bregaba por la revolución social y sexual. En poco tiempo el grupo creció y llegó acaudillar más de diez grupos en los que se integraron peronistas, marxistas, anarquistas, católicos, trabajadores, intelectuales e importantes figuras literarias como Manuel Puig. Desplegaron actividades variadas como escribir manifiestos teóricos, publicar la revista Somos con temáticas homosexuales, repartir panfletos y participar en manifestaciones (Simonetto 2017: 10-55).

El FLH ocupó gran parte de su actividad en cuestionar las políticas coactivas del Estado argentino contra los homosexuales. En 1973, publicaron una "Cartilla de seguridad" que proponía métodos para evitar sanciones policiales: citaba derechos civiles que protegían la integridad personal y explicaba lo que debían hacer las personas si eran detenidas: firmar en disconformidad para evitar que el comisario ocupara el lugar del juez y así ser trasladado a un juzgado donde su posibilidad de evitar el encarcelamiento era mayor. En ese mismo número de Somos apareció un comunicado titulado "La tía Margarita impone la moda Cary Grant", en el que se hacía público el rechazo a las acciones de Luis Margaride, policía reconocido por su aplicación de los códigos de falta. El itinerario y la permanencia de este funcionario expresó la continuidad de las políticas restrictivas hacia las sexualidades no hegemónicas entre gobiernos civiles y militares. Más adelante se anunciaba una colecta de fin de año para los 
presos del pabellón quinto bis de la cárcel de Devoto, que era reservado para los homosexuales (Somos 1973, núm. 1).

En sus intentos de popularizar su programa de revolución sexual, el FlH se aproximó al peronismo. En 1973 sus representantes se hicieron presentes en las manifestaciones de Ezeiza y Plaza de Mayo para festejar el retorno de esta tendencia política al gobierno y dieron una entrevista al semanario Así en la que propusieron un mensaje más masivo valiéndose de la figura de Evita y de consignas nombradas en la marcha peronista como "para que en el pueblo reine el amor y la igualdad". Pero un sector de la derecha peronista empapeló la ciudad con la frase: "El ERP, los homosexuales y drogadictos", y la izquierda peronista recibía al grupo de homosexuales en las manifestaciones con la injuria: "No somos putos, tampoco faloperos, somos soldados de Evita y Montoneros". Héctor Anabitarte recuerda: "Llevábamos con timidez una pancarta que nos identificaba. Las columnas que venían adelante y atrás dejaron un espacio para no confundirse con nosotros, los putos. Vivíamos de marginación en marginación". Las libertades democráticas del gobierno de Héctor Cámpora (1973) permitieron a este grupo disfrutar de una expresión pública más visible. Néstor Latrónico señala que, gracias a arreglos llevados a cabo por el sociólogo Néstor Perlongher, pudieron asistir a Ezeiza a recibir a Perón junto a la Juventud Peronista (JP). Pero su participación con banderas y pancartas que solicitaban el fin de las persecuciones por su condición sexual fueron respondidas con rechazo por algunos asistentes. En la manifestación les cantaban: "No somos putos, tampoco faloperos, somos hijos de FAR y Montoneros". A pesar de sus intentos, había por el momento una frontera infranqueable entre el FLH y el peronismo (Simonetto 2017). Esto llegó a su fin cuando en 1974 las políticas de restricción estatal se intensificaron con la nueva presidencia de Perón. El FLH propuso entonces instancias de coordinación y convergencias con las feministas de la Unión Feminista Argentina y el Movimiento de Liberación Femenina, y el trotskismo, el Partido Socialista de los Trabajadores, con los que emprendieron grupos de lectura y divulgación de las teorías de la revolución sexual (Grupo de Política Sexual) y acciones de lucha. En 1974, frente a la prohibición 
de la venta de anticonceptivos construyeron una coordinadora que declaró: "Con el pretexto de una política poblacional que cubra las necesidades de nuestro país, el reciente decreto de anticonceptivos viola el derecho fundamental humano de asumir la responsabilidad de su paternidad [...]. Estas medidas se ligan a las siniestras campañas de moralidad, las razzias contra la juventud y el accionar terrorífico e intimidatorio" (Coordinadora contra la Prohibición de Venta de Anticonceptivos, 1974).

Finalmente, el grupo comenzó a disolverse cuando la violencia política del Estado y la extrema derecha se hicieron presentes. En 1975, El Caudillo, expresión pública de la Alianza Anticomunista Argentina (AAA) incitó a acabar con los homosexuales. Proponía "crear brigadas callejeras que salgan a recorrer los barrios para que den caza a estos sujetos vestidos como mujeres, hablando como mujeres, pensando como mujeres. Cortarles el pelo en la calle o raparlos y dejarlos atados en los árboles con leyendas didácticas" (El Caudillo, núm. 75). El FLH respondió públicamente con un volante titulado "El fascismo nos amenaza" (1975). Anunció a sus "hermanos y hermanas que la hora de unión total y sin claudicaciones ha llegado: los homosexuales argentinos debemos unirnos sin vacilaciones para defender nuestro derecho a la libertad y a la vida, y enfrentar a nuestro enemigo común: el fascismo [...] si deponemos nuestros miedos personales en beneficio de todos, podremos vencer y conquistar la dignidad humana que se nos niega". El miedo terminó por disolver a la organización y muchos de sus miembros debieron exiliarse antes de iniciarse la política genocida de 1976 ("El fascismo nos amenaza" 1975).

En Chile, en la década de 1980 aparecen las primeras expresiones políticas de la disidencia sexual. Previamente existieron resistencias políticas que fueron reprimidas inmediatamente, o bien, relaciones homoeróticas que desafiaban las normativas moralizantes. A pesar de la criminalización y la carga negativa sobre la homosexualidad, las prácticas homoeróticas se produjeron de forma clandestina, tanto en espacios públicos como privados dentro de grandes ciudades, desafiando de alguna forma las leyes que, precisamente, penalizaba dichas prácticas. La Plaza de Armas de Santiago, conocida como un centro de encuentro cultural-artístico importante den- 
tro de la ciudad, también se caracterizó por la bohemia que los mismos círculos intelectuales y artísticos generaban. Esto también sirvió como un espacio de encuentros homoeróticos clandestinos durante tardes y noches, y para el ejercicio de la prostitución masculina por parte de jóvenes a cambio de ropa, comida, invitaciones o por dinero (Salazar 2017).

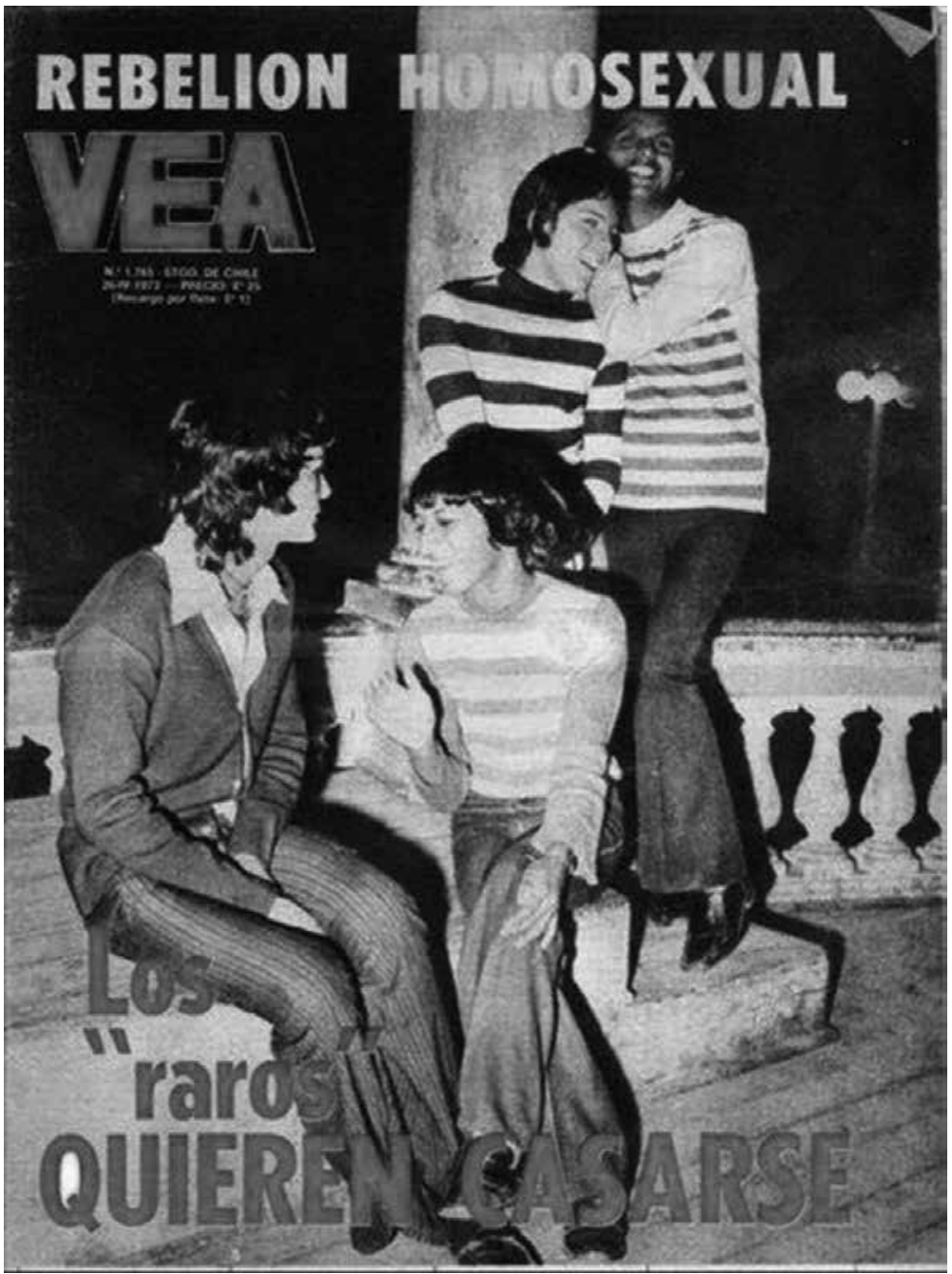

FueNTE: Vea, núm. 1765, 26 de abril de 1973. 
Lo que explica la primera movilización homosexual registrada en Chile en 1973 en pleno gobierno de la Unidad Popular, en donde un grupo de 25 personas de estrato popular protestaron en la Plaza de Armas de Santiago para demandas el abuso policial que, precisamente, se validaban en el artículo 373 y 365 del Código Penal chileno (Robles 2008). Paralelo a esto, otros sitios de encuentros anónimos y clandestinos fueron cines, parques y baños públicos, además de prostíbulos ubicados en distintas partes de Santiago que incluían oferta de prostitución homosexual travesti junto con prostitutas mujeres (Contardo 2011).

Las transiciones democráticas en Argentina (1983) y Chile (1989), con sus particularidades, generaron debates por la redefinición de los usos sexuales del espacio público. En el contexto de un proceso de globalización de la identidad gay en occidente y sus interpretaciones locales (Laguarda 2009), se concretaron distintas iniciativas para resolver y movilizar las demandas en busca de eliminar las violencias estatales y plantear nuevos derechos. La codificación de una nueva agenda política anclada en las libertades democráticas para expresar la sexualidad, como también la confluencia con los discursos de los derechos, humanos implicaron la pérdida de los filos radicales de estos movimientos y la búsqueda de una progresiva integración a los regímenes democráticos y liberales.

Estas transformaciones estuvieron limitadas por los estigmas sociales asociados a la homosexualidad masculina, el lesbianismo y la transexualidad. Por ejemplo, la crisis del VIH-sida en Chile en las décadas de 1980 y 1990 generó un clima de estigmatización que legitimó el rechazo y resistencia hacia la homosexualidad masculina. Incluso en los años noventa, cuando hubo presencia de los primeros homosexuales en la televisión chilena, éstos eran rechazados por la opinión pública de la década (Guajardo 2018). Más intensa fue la sanción social hacia mujeres trans, quienes eran relacionadas directamente con el virus por los medios de comunicación debido a sus vínculos con el comercio sexual (Barrientos y Garrido 2018). Particularmente en el caso chileno, los altos índices de contagio y fallecimientos a causa del virus generaron un contexto de miedo hacia la enfermedad y a sus principales portadores - en ese tiempo asociado a 
la homoexualidad y promiscuidad-. Hacia 1997, se calculaba entre 18.000 a 19.000 casos de personas seropositivas, situación que empeoraba en un país que todavía no tenía una política de financiamiento y apoyo con los medicamentos (La Tercera 1997).

La transición democrática en Chile permitió la apertura de nuevos debates sobre derechos humanos y ciudadanía, por lo mismo, hubo una ampliación de la esfera pública hacia nuevas discusiones que, durante la dictadura militar, no se plantearon. El Movimiento por la Liberación Homosexual (Movilh Histórico), primera agrupación política LGBTQ en el país, se creó en 1991 en un taller de derechos civiles organizado por la Corporación Chilena de Prevención del sida. En dicho taller se creó el primer espacio para reflexionar sobre la discriminación por orientación sexual en Chile, debates que sentaron los primeros lineamientos ideológicos y políticos para una posible liberación homosexual, lo que culminó con la creación del Movilh Histórico (Robles 2008). Una de las primeras luchas fue la derogación de la ley de penalización de la sodomía, ya que era considerada como una forma de criminalizar la homosexualidad. Para esto, el Movilh Histórico participó en las discusiones parlamentarias orientadas en modificar el Código Penal -lo cual incluía modificar la ley de penalización de la sodomía-, planteando que dicha ley simbolizaba una discriminación hacia la población homosexual, al mismo tiempo que apelaban a no más represión contra la comunidad LGBTQ (Historia de la Ley núm. 19.917 1999: 195). De hecho, para la agrupación, la despenalización de la ley significó: "el fin de una época en que los homosexuales hemos debido mantenernos ocultos para evitar el castigo y rechazo hacia nuestras personas" (Garrido y Barrientos 2018: 9). Los debates internos del Movilh Histórico concentrados en diagnosticar y analizar la homofobia en Chile dejaron en un segundo plano otros temas como la trans y lesbofobia, o incluso la problemática del viH-sida en el país, lo que generó que hacia finales de los noventa la agrupación se dividiera y aparecieran nuevas agrupaciones concentradas en abordar problemáticas específicas de la población gay, trans y lésbica: la aparición de estos nuevos movimientos permitió ampliar el concepto de ciudadanía y de derechos humanos en el país, además de 
denunciar nuevos tipos de discriminación, como las que sufren directamente lesbianas y personas trans (Hiner y Garrido 2017). A finales de la década de 1990, surgieron nuevos grupos como Centro Lambda, el Movimiento Unificado de Minorías Sexuales (Mums), Traves Chile y el Sindicato Amanda Jofré - ambas organizaciones trans-, y los grupos lésbicos Rompiendo el Silencio y la Coordinadora Lésbica-Feminista.

En Argentina, la emergencia de nuevos movimientos por los derechos de gays, lesbianas y travestis se gestó en consonancia con la nueva presencia que adquirieron los agrupamientos por los derechos humanos (Bellucci 2010). Entre 1980 y 1990 se multiplicaron agrupaciones como la Comunidad Homosexual Argentina, Grupo Federativo Gay, Grupo de Acción Gay, Movimiento de Liberación Homosexual de Rosario, Cuadernos de Existencia Lesbiana, Gays Derechos Civiles, Frente de Lesbianas, Travestis Unidas, Asociación Travestis Argentina y Arco Iris, entre otros. En contraste con la estrategia de la década de 1970, mediados por una batalla por el carácter de la nueva democracia conquistada tras la caída del régimen y la globalización de nuevas identidades sexuales como lo gay, estos agrupamientos articularon tácticas heterogéneas para disputar en el orden legal (Theumer 2017).

A partir de 1983, la cHA comenzaría una campaña pública de visibilidad y denuncia a la represión. Demandaría reuniones al gobierno de Raúl Alfonsín y presentaría solicitadas públicas reclamando los ceses de despidos discriminatorios y la anulación de los edictos policiales, política que sostendrán hasta lograr los cambios normativos (Clarín 1984). En 1985, las estrategias frente a las elecciones legislativas fueron múltiples: El Movimiento Gay Bonaerense presentó a Raúl Soria como candidato extrapartidario del Partido Humanista, lo que anunció la llegada de la primera candidatura de un varón públicamente gay (Crónica 1985). La CHA cuestionó a los candidatos a legisladores acerca de sus opiniones sobre los derechos gay, práctica política que reiterarían en cada elección y que a partir de 1993 se transformaría en la campaña "no vote a candidatos/as que discriminan". En 1986, inició una campaña en la provincia de Buenos Aires para reformar la ley electoral provincia 5109 sancionada durante el peronismo en 1946 
que inhabilitaba a los homosexuales a ejercer el voto. Campaña que tuvo cierto éxito y terminó con la derogación de dicho artículo (Crónica 1986).

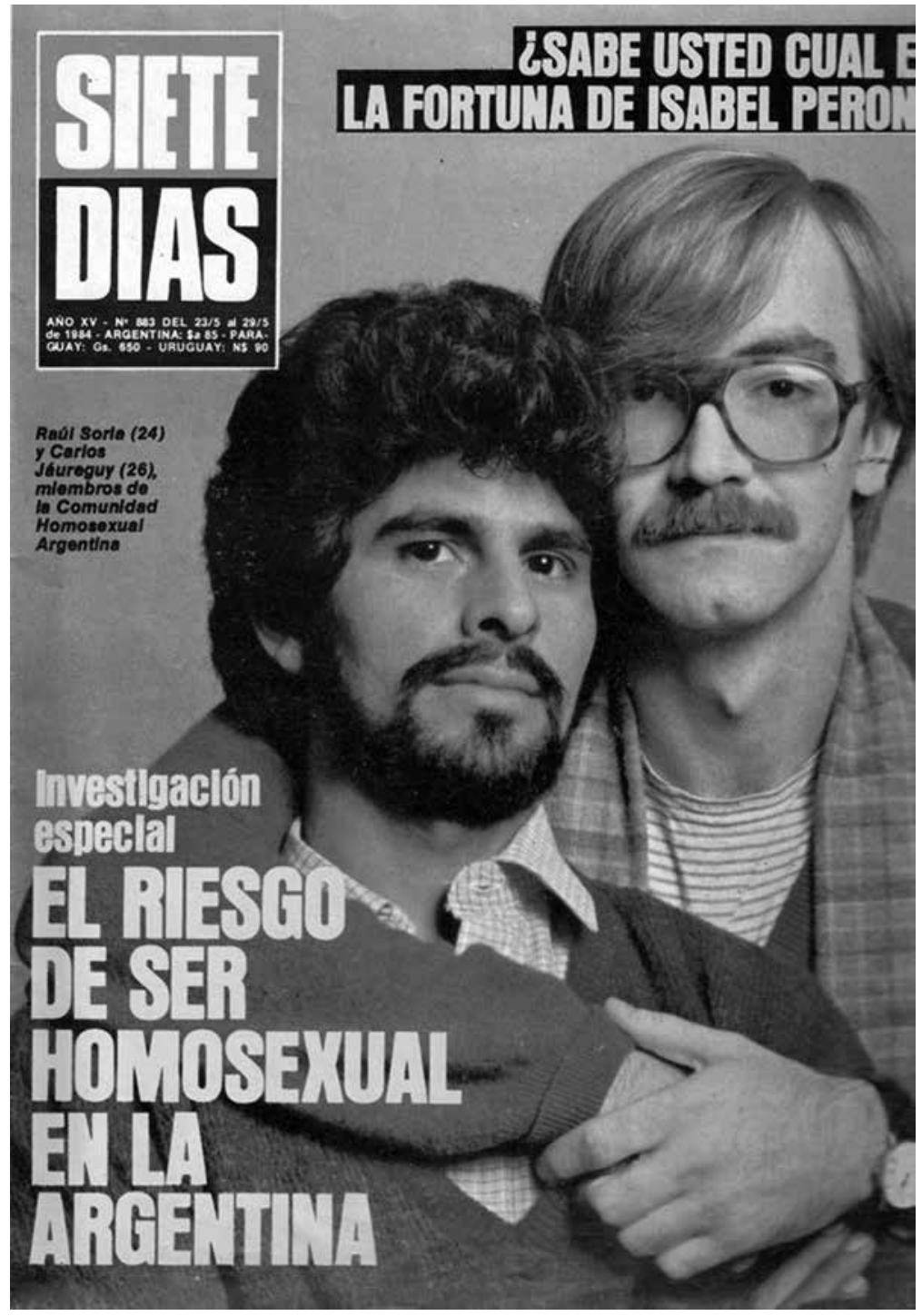

Fuente: Revista Siete Días, 2 de mayo de 1984. 
En 1988 las lesbianas organizaron una primera actividad de visibilización pública en el Congreso. A inicios de la década 1990 se reunían en Buenos Aires organizaciones como "Fresas", luego denominada "Frente Sáfico", y "Las Unas y las Otras" (Mogrovejo 2000: 290-291). Los/as activistas recurrieron a la visibilidad como una herramienta de acción política. La referente lesbiana Ilse Fuskova participó del programa de Mirtha Legrand en 1991, como así también, el referente de la CHA Carlos Jáuregui, un profesor universitario, concedió entrevistas en las que afirmó que había más de un millón y medio de homosexuales en el país, habló abiertamente del SIDA y de la vida homosexual en pareja (Revista Siete Días 1984). En 1987, Carlos Jáuregui, quien era profesor universitario, escribió el libro $L a$ bomosexualidad en Argentina.

Los intentos de institucionalización no fueron sencillos. El 7 de diciembre de 1989 el inspector general de justicia denegó la personería jurídica a la CHA y en 1990 la decisión fue convalidada por la Sala Civil I (Clarín 1990). Lo que derivó en una profusa lucha pública por el reconocimiento, personería que conseguirían en 1992. Ese mismo año se organizó la primera Marcha del Orgullo Gay-Lésbico desde Plaza de Mayo al Congreso de la Nación (Meccia 2006).

Con el telón de fondo de las reformas neoliberales comandadas por Carlos Menem entre 1989 y 1999, la declaración de la autonomía de la ciudad de Buenos Aires habilitó disputas contra los mecanismos de control del territorio. En 1996, los movimientos LGTB consiguieron que en la constitución de la ciudad se estableciera la prohibición de la discriminación por la orientación sexual; y en 1998, con un papel destacado de las travestis, transexuales, trabajadoras sexuales y organismos de derechos humanos, se derogaron los edictos policiales (Barrancos, 2014). A pesar de ello, normativas similares siguieron vigentes en distintas provincias y las prácticas policiales irregulares continuaron penando en particular a la comunidad travesti y transexual. La despenalización de la sodomía en Chile en 1999 generó debates sobre la ampliación de derechos para gays, lesbianas, transexuales y bisexuales que embarcó a las principales organizaciones de la diversidad sexual. 
Durante las primeras dos décadas del siglo XXI ambos países vivieron un proceso de ampliación de la agenda de temas en torno a la ciudadanía sexual: matrimonio igualitario, ley de identidad de género, adopción homoparental, entre otras. A su vez, la apropiación del lenguaje de la "ciudadanía" por parte de grupos políticos de la diversidad sexual allanó el camino hacia la institucionalización como producto del fortalecimiento de los regímenes democrático-liberales.

\section{Conclusiones}

Toda política es sexual en cuanto moviliza expectativas, regula e imagina actores que interconectan vidas públicas, privadas e íntimas. En este artículo nos referimos en particular a aquellas políticas con las que agencias de los Estados de Argentina y Chile construyeron una frontera entre ciudadanos heterosexuales y ciudadanos homosexuales; mostramos un panorama sobre cómo establecieron límites de género, clase y edad para los usos posibles del espacio urbano; también resaltamos las formas de acción y creación de movimientos de la disidencia sexual durante el siglo XX. Los resultados de estas luchas se concretaron hacia finales del siglo XX con trayectorias bastante complejas: en Argentina las leyes de Matrimonio Igualitario (núm. 26.618) y de Identidad de Género (núm. 26.743); en Chile, la Ley de Unión Civil (núm. 20.830), ley que establece medidas contra la discriminación, conocida como Ley Zamudio (núm. 20.609) y, recientemente, la Ley que reconoce y da protección al derecho a la identidad de género (núm. 21.120), marcaron un ciclo de institucionalización y redefinición normativa del carácter sexual de la ciudadanía en ambos países. Lo que no ha significado que las políticas informales de coacción cesaran, tal como lo escenifica la reciente interpelación del Comité contra la Tortura de la Organización de Naciones Unidas al Estado argentino por la persecución, tortura y asesinato de travestis y transexuales.

Este artículo propone al menos dos síntesis generales. Primero, que la consolidación de la noción de moral pública y el progresivo poder otorgado 
a policías (Argentina) y carabineros (Chile) estuvo asociada a una interpretación conservadora de las elites frente a las presuntas transformaciones urbanas que amenazaban las condiciones materiales de su identidad nacional. Así, ante las turbulencias del proyecto liberal, se pusieron en uso (Chile) o se sancionaron normativas (Argentina) de control del espacio que definieron el carácter clasista y sexuado de su uso. Además, a pesar de la alternancia entre gobiernos civiles y militares, si bien la intensidad de las violencias cambió, estas políticas tuvieron un carácter continuo durante gran parte del siglo Xx. Contra estas iniciativas e inspirados por transformaciones profundas en los campos políticos de cada país emergieron respuestas significativas. En Argentina, un primer ciclo estuvo marcado por la interpretación radical de la identidad homosexual y el despliegue de políticas que intentaron construir un puente entre el imaginario de la revolución social y sexual. En Chile, inspirados en la ebullición de expectativas movilizadas por el gobierno de la Unidad Popular, grupos dispersos se manifestaron para denunciar los altos grados de violencia a los que eran sometidos.

Las salidas democráticas a los regímenes castrenses violentos de ambos países abrieron un escenario de disputas en el que intervinieron movimientos gays, travestis y lésbicos. Al calor de la propagación de las nuevas identidades globales e interpelados por el discurso de los derechos humanos, la radicalidad cedió lugar a una agenda ligada a las transformaciones de los derechos civiles. A pesar de ello, el proceso de institucionalización no disolvió las batallas de estos agrupamientos por las violencias que atentan contra las vidas de las sexualidades disidentes. Además, la institucionalización de algunos grupos trajo consigo también la emergencia de activismos disidentes que tensionaron este proceso. Aunque no sin dificultades, en ambos países el desarrollo de estas luchas permitió disolver los núcleos normativos de las políticas de restricción violenta del Estado como parte de un ciclo de mutación de las identidades sexuales y, por tanto, un proceso de ampliación del concepto de ciudadanía, incorporando nuevas identidades sexuales y de género en pleno siglo XXI. De esta forma, nos aproximamos a una historia comparada sobre las políticas sexuales restrictivas en ambos países y las resistencias de sujetos disidentes. 
BIBLIOGRAFÍA

Acevedo, Claudio y Elgueta Eduardo. "El discurso homofóbico en la prensa izquierdista durante la Unidad Popular", Revista Izquierdas 2. 3 (2009).

ACHa, Omar y Ben Pablo. "Amorales, patoteros, chongos y pitucos. La homosexualidad masculina durante el primer peronismo [Buenos Aires, 1943-1955]". Trabajos y Comunicaciones 30-31 (2004).

Anuario Estadístico 2014. Ciudad de Buenos Aires. Buenos Aires: Dirección General de Estadísticas y Censos (Ministerio de Hacienda GCBA), 2015.

ALEGRE, ROBERT F. "Sodomitic Violence in Chile. Medical Knowledge and the Ambivalent Application of Law". Violence and Crime in Latin America: Representations and Politics. Gema Santamaría y David Carey (eds.). Norman: University of Oklahoma Press, 2017. 103-118.

BALDERSTON, DANIEL y DONNA GUY. Sex and Sexuality in Latin America: An Interdisciplinary Reader. Nueva York: NYU Press, 1997.

BaO, Daniel. "Invertidos Sexuales, Tortilleras, and Maricas Machos: The Construction of Homosexuality in Buenos Aires, Argentina, 19001950". Journal of Homosexuality 24. 3-4 (1993): 183-220.

BARRANCOS, DORA. "Géneros y sexualidades disidentes en la Argentina: de la agencia por derechos a la legislación positiva". Cuadernos de Intercambio sobre Centroamérica y el Caribe 11. 2 (2014): 17-46.

tion in Twentieth-Century Argentina". Journal of Women's History 18.2 (2006): 123-150.

BelluCCI, MABEL. Orgullo: Carlos Jáuregui, una biografía política. Buenos Aires: Emecé, 2010.

BOHOSLAVSKY, ERNESTO. "América Latina (1950-1989): perspectivas desde la historia comparada". Quinto Sol 19. 1 (2015): 1-3.

Chauncey, George. Gay New York: Gender, Urban Culture, and the Making of the Gay Male World, 1890-1940. uK Hachette: 2008. 
Coelho, Prado, María Ligia. "América Latina: historia comparada, historias conectadas, história transnacional". Anuario de la Escuela de Historia 24 (2013): 9-22.

CONTARDO, ÓSCAR. Raro. Una historia gay de Chile. Santiago: Planeta, 2011. Cornejo, Juan. "Configuración de la homosexualidad medicalizada en Chile". Sexualidad, Salud y Sociedad. Revista Latinoamericana 9 (2011).

Corrales, Javier, y Mario PeCheny. The Politics of Sexuality in Latin America. Pittsburg: University of Pittsburgh Press, 2010.

Cowan, BEnjamin. Securing Sex: Morality and Repression in the Making of Cold War Brazil. Chapel Hill: unC Press Books, 2016.

DraYTON, Richard y DAVID MOTADEL. "Discussion: the Future of Global History". Journal of Global History 13.1 (2018): 1-21.

FIGARI, CARLOS. Eróticas de la disidencia en América Latina: Brasil, siglos XVII al XX. Buenos Aires: CLACSO, 2009.

. "El movimiento LGBT en América Latina: institucionalizaciones oblicuas". Movilizaciones, protestas e identidades politicas en la Argentina del bicentenario. Astor Massetti, Ernesto Villanueva y Marcelo Gómez (comps.). Buenos Aires: Nueva Trilce, 2010. 225-240. GaRRIDO, JuAn CARLOS. "Historias sobre un rosa amanecer. El movimiento homosexual y la transición democrática en Chile". Revista Historia en Movimiento IV. 4 (2017): 94-107.

y Claudio Barrientos. "Identidades en transición: prensa, activismo y disidencia sexual en Chile, 1990-2010". Psicoperspectivas 17.1 (2018): 17-27.

GILBERT, ALAN. La ciudad latinoamericana. México: Siglo XXI, 1997.

Guajardo, Gabriel. Diversidad y vih/sida en el espacio público. Escritos prácticos (1993-2011). Santiago: Flacso-Chile, 2018.

Herzog, Dagmar. Sexuality in Europe: A Twentieth-Century History. Vol. 45. Cambridge: Cambridge University Press, 2011.

Hiner, Hillary y Juan Carlos GaRrido. "Porque ser pobre y maricón es peor': la violencia antiqueer en Chile, 2000-2012". Malestar social 
y desigualdades en Chile. María Antonieta Vera (ed.). Santiago: Ediciones Universidad Alberto Hurtado, 2017. 195-223.

HubBarD, PHIL. Cities and Sexualities. Routledge: Critical Introduction to Urbanism and the City, 2013.

LAGUARDA, RODRIGO. Ser gay en la ciudad de México: lucha de representaciones y apropiación de una identidad, 1968-1982. Centro de Investigaciones y Estudios Superiores en Antropología Social, 2009.

Mallon, FloRencia. "Barbudos, Warrior, and Rotos: The MIR, Masculinity and Power in the Chilean Agrarian Reform". Changing Men and Masculinities in Latin America. Matthew C. Gutmann (ed.). Durham y Londres: Duke University Press, 2003. 179-215.

MeCCIA, ERNeSto. La cuestión gay: un enfoque sociológico. Buenos Aires: Gran Aldea Editores, 2006.

MOgROVEJO, NORMa. Un amor que se atrevió a decir su nombre: la lucha de las lesbianas y su relación con los movimientos homosexual y feminista en América Latina, México, Plaza y Valdés, 2000.

MotT, Luiz RoBerTo. Epidemic of Hate. Violations of the Human Rights of Gay Men, and Travesties in Brazil. San Francisco: Grupo Gay da Bahia/International Gay and Lesbian Human Rights Comission, 1996. Power, Margaret. "La Unidad Popular y la masculinidad". La Ventana 6 (1997): 250-270.

RAMACCIOTTI, Karina InÉS y ADRIANA María VAlOBRa. "El campo médico argentino y su mirada al tribadismo, 1936-1955". Estudos Feministas 16. 2 (2008): 493-516.

ROBLES, VícTOR. Bandera hueca: historia del movimiento homosexual de Chile. Santiago: Cuarto Propio, 2008.

ROMERO, LuIS. Qué bacer con los pobres. Elite y sectores populares en Santiago de Chile, 1840-1895. Buenos Aires: Sudamericana, 1997.

SABSAY, LETICIA. Fronteras sexuales. Espacio urbano, cuerpos y ciudadanía. Buenos Aires: Paidós, 2011.

SALESSI, JORGE. Médicos maleantes y maricas: higiene, criminología y bomosexualidad en la construcción de la nación argentina (Buenos Aires, 1871-1914). Rosario: Beatriz Viterbo, 1995. 
SCHEUZGER, STEPHAN. "La historia contemporánea de México y la historia global: reflexiones acerca de los 'sesenta globales'”. Historia mexicana 68. 1 (2018): 313-358.

SimonetTo, Patricio. "Intimidades disidentes. Intersecciones en las experiencias de homosexuales y lesbianas en Buenos Aires durante los sesenta y setenta". Trashumante: Revista Americana de Historia Social 11 (2018): 28-50.

. "La moral institucionalizada. Reflexiones sobre el Estado, las sexualidades y la violencia en la Argentina del siglo xx". el-@tina.Revista Electrónica de Estudios Latinoamericanos 14. 55 (2016): 1-22. "Movimientos de liberación homosexual en América Latina. Aportes historiográficos desde una perspectiva comparada entre Argentina, Brasil, Chile, Colombia y México (1967-1982)". Iberoamericana 17. 65 (2017a): 157-177.

- Entre la injuria y la revolución: el Frente de Liberación Homosexual. Argentina, 1967-1976. Argentina: UNQ, 2017b.

SOPRANO, GERMÁN. "El ombudsman militar: conflictos entrederechos ciudadanos y orden castrense en la Argentina del Siglo XX". Revista Quaestio Iuris 8.2 (2015): 718-734.

STEARNS, PETER. Sexuality in World History. usa: Routledge, 2017.

Sutherland, JuAn Pablo. Nación marica. Prácticas culturales y crítica activista. Santiago: Ripio Ediciones, 2009.

Theumer, Emmanuel. "Políticas homosexuales en la Argentina reciente (1970-1990s)". Interdisciplina 5. 11 (2017): 109-126.

\section{FUENTES DOCUMENTALES}

\section{Legislación}

Decreto 378/45. Gobierno de la Provincia de Buenos Aires. 1945. Decreto 873/50. Gobierno de la Provincia de Buenos Aires. 1950. Ley 8031. Gobierno de la Provincia de Buenos Aires. 1973. 
Ley Provincial 5571. Gobierno de la Provincia de Buenos Aires. 1956.

Historia de la Ley núm. 19.617. Modifica el Código Penal, el Código de Procedimiento Penal y otros cuerpos legales, en materias relativas al delito de violación. Santiago: Biblioteca del Congreso Nacional de Chile, 1999.

Artículos de prensa

"El riesgo de ser homosexual en la Argentina". Revista Siete Días, Buenos Aires. 2 de mayo de 1984.

"Entrevista al candidato gay". Crónica, Buenos Aires. 1 de abril de 1986. "La moral no pasa de moda". Clarín, Buenos Aires. 12 de mayo de 1966. "Leve progreso latinoamericano para impedir avance del sida". La Tercera, Santiago. 29 de agosto de 1997.

"Los homosexuales denuncian persecución". Clarín, Buenos Aires. 1 de febrero de 1984.

"Los homo piden ir al cuarto oscuro". Crónica, Buenos Aires. 1 de abril de 1986.

"Niegan la personería a la comunidad homosexual". Clarín, Buenos Aires. 22 de agosto de 1990.

\section{Panfletos}

"Coordinadora contra la prohibición de ventas de anticonceptivos". 1974. Panfleto.

"El fascismo nos amenaza". 1975. Panfleto. 